\title{
Primary osteoporosis in children
}

\author{
Lay Ong Tan, ${ }^{1}$ Soo Yen Lim, ${ }^{2}$ Rashida Farhad Vasanwala ${ }^{3}$
}

'Department of Paediatrics, KK Women's and Children's Hospital, Singapore, Singapore ${ }^{2}$ Department of Family Medicine, SingHealth Polyclinics, Singapore, Singapore ${ }^{3}$ Department of Paediatrics, Endocrinology Service, KK Women's and Children's Hospital, Singapore, Singapore

\section{Correspondence to} Dr Lay Ong Tan, philiptan83@gmail.com limsooyen688@hotmail.com

Accepted 10 August 2017

\section{SUMMARY}

Osteoporosis in childhood is uncommon, and it may be secondary to a spectrum of diverse conditions. Idiopathic juvenile osteoporosis is a primary osteoporosis of unknown aetiology present in previously well children and is a diagnosis of exclusion. We describe a 10-yearold prepubertal boy who presented with back pain of 1-week duration. His spinal X-ray showed generalised loss of vertebral body heights in keeping with osteoporosis. Endocrine and haematological work-up were normal. He was treated with vitamin D supplement and intravenous pamidronate. This case illustrates the general work-up and causes for paediatric osteoporosis, and the management for idiopathic juvenile osteoporosis.

\section{BACKGROUND}

Osteoporosis in general has been considered an adult disease, but osteoporosis that is symptomatic during childhood is emerging as a newly recognised problem among at-risk individuals, especially chronically ill children. Recognition of causes of primary and secondary osteoporosis and the role of bisphosphonates are illustrated here.

\section{CASE PRESENTATION}

A 10-year-old Chinese boy was seen in the children's emergency for concerns of intermittent back pain of 1-week duration, worsened by an episode of fall. He experienced immediate pain and inability to walk. He had no significant medical history of bone pain, recurrent fractures, chronic medical illness or treatment with long-term steroids. There is no family history of recurrent fractures or premature osteoporosis. He is an active basketball player and his diet is adequate in milk and dairy intake. On examination, he was proportionate with height of $137 \mathrm{~cm}$ (50th centile) and weight of $47.1 \mathrm{~kg}$ (90th centile), and midparental height of $172.3 \mathrm{~cm}$ (25 th centile). There was tenderness over the entire spine, with thoracic kyphosis, and neurological examination was normal with intact sensation. He had no cushingoid features and was prepubertal. He was admitted for further work-up and management of his back pain.

\section{CrossMark}

To cite: Tan LO, Lim SY, Vasanwala RF. BMJ Case Rep Published Online First: [please include Day Month Year]. doi:10.1136/bcr-2017 220700

\section{INVESTIGATIONS}

Initial investigation included spine X-ray (figure 1), which showed reduced anterior vertebral body heights of thoracic and lumbar vertebrae suggestive of compression fracture and diffuse osteopaenia.

Investigations were done to exclude secondary causes of osteoporosis. Endocrine work-up included thyroid function, bone profile, synacthen, prolactin, insulin-like growth factor 1 (IGF-1) and 24-hour free cortisol, which were all normal. Bone age was consistent with chronological age. Dexamethasone suppression test was not suggestive of Cushing disease, and 25 hydroxyvitamin D level was in sufficiency range.

Further investigations included bone marrow aspirate, which showed no blast cells and normal chromosome analysis. Autoimmune and inflammatory markers were normal. MRI spine showed generalised loss of the vertebral body heights from T4 to L5 in keeping with osteoporosis. MRI spine was done as part of the evaluation to rule out chronic infection, primary tumour and metastasis, which can present with vertebral compression fractures. Coeliac screen was not performed due to low pretest probability in the ethnic Chinese population, and his height and weight were appropriate for his age.

\section{DIFFERENTIAL DIAGNOSIS}

Primary osteoporosis such as osteogenesis imperfecta was less likely as there was no blue sclerae, no dentinogenesis imperfecta and negative family history. There was no dysmorphism suggestive of Marfan syndrome and no joint laxity suggestive of Ehlers-Danlos syndrome.

Secondary osteoporosis is caused by chronic disease or the steroid therapy used to treat it. There was no evidence of chronic illnesses such as inflammatory bowel disease (no change in bowel habit), chronic renal disease (normal renal profile) and steroid-dependent asthma. Endocrine diseases such as hyperthyroidism (normal thyroid function test), growth hormone deficiency (normal IGF-1 level) and Cushing syndrome (normal dexamethasone suppression test) were also excluded. Other causes included metabolic disease such as Wilson disease (unlikely as he had no neuropsychiatric presentation and his liver function test was normal), homocystinuria (unlikely as he did not have Marfanoid habitus, learning difficulties or joint stiffness) and atypical coeliac disease (unlikely as coeliac disease is not common in Chinese population). There was no chronic use of glucocorticoids and no evidence of malignancy from bone marrow aspiration.

\section{TREATMENT}

He was diagnosed with idiopathic juvenile osteoporosis (IJO). The main strategy of treatment was protection of the spine until remission occurred. He was initially started on calcium carbonate and vitamin D tablet once daily. Vitamin $\mathrm{D}$ therapy was used to optimise bone health in view of osteoporosis, although the therapy does not treat 


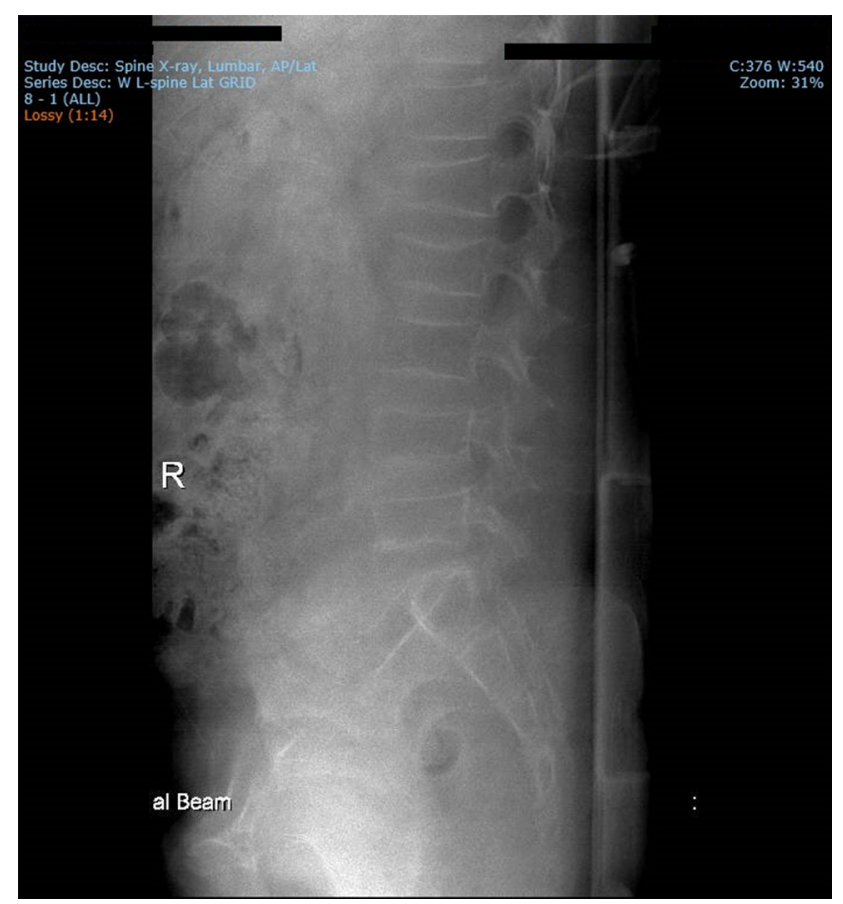

Figure 1 Lumbar spine X-ray showed reduced anterior vertebral body heights of L1 and L2 vertebrae and diffuse osteopaenia.

IJO. Physiotherapy was commenced for strengthening exercises and posture correction.

\section{OUTCOME AND FOLLOW-UP}

He was discharged after 4 days of inpatient stay as his back pain improved, with follow-up with the endocrine and orthopaedic team. The beneficial role of early bisphosphonate treatment was explained to the parents especially with regard to improvement in vertebral morphology, but they decided to wait and watch for spontaneous resolution with onset of puberty.

Although his back pain improved, there was no improvement in the height-adjusted $\mathrm{Z}$ score, measured by dual-energy X-ray absorptiometry (DXA) scan, and therefore pamidronate was initiated $1 \frac{1}{2}$ years post initial presentation. As IJO is an uncommon cause of primary osteoporosis in children and is a diagnosis of exclusion, the patient needed detailed evaluation to exclude all secondary causes, and parents wanted to wait for spontaneous resolution initially and hence the delay in starting pamidronate. Intravenous pamidronate was given for four doses in total ( $1 \mathrm{mg} / \mathrm{kg} /$ dose over 4 hours, every 3 months).
Table 1 illustrates bone mineral density (BMD) readings and height-adjusted $\mathrm{Z}$ score for lumbar spine and left hip, respectively, from 2012 until 2015.

He has been asymptomatic throughout the 4 years of follow-up, with improvement of thoracic kyphosis and normal growth velocity. His puberty commenced at the age of 12 years. His BMD normalised at the age of 13 years and 3 months in the middle of his puberty.

\section{DISCUSSION}

Idiopathic juvenile osteoporosis (IJO) is a term applied to a primary osteoporosis of unknown aetiology present in previously well children. It is a rare, usually self-limiting disorder of bone pain and fractures. ${ }^{12}$ Incidence is 1 in 100000 and onset is typically between ages 8 and 14 years coinciding with 2-3 years prior to puberty, ${ }^{3}$ as in our patient. The main presenting symptoms included long bone fractures, back pain and difficulty in walking, as reported in a clinical cohort of 21 patients with IJO. ${ }^{4}$ They may have dental findings such as atypical crown morphology and congenital oligodontia, ${ }^{5}$ which were absent in our patient.

The diagnosis of IJO is based on clinical and radiographic findings after exclusion of other common primary or secondary forms of osteoporosis, including congenital conditions such as osteogenesis imperfecta, homocystinuria, Turner syndrome, and acquired conditions such as coeliac disease, malignancy and steroids usage.

In patients with IJO, there is decreased bone formation, in the absence of increased bone resorption or cortical damage, in the trabecular bone, as shown in the histomorphometric data by Rauch and Bishop. ${ }^{6}$ This was further supported by cross-sectional analysis by Bacchetta et $a l^{7}$, which showed decreased bone turnover and decreased trabecular and cortical $\mathrm{Z}$ scores for bone mineral density using quantitative CT scan and bone histomorphometry for a cohort of 15 patients with IJO. Transiliac bone biopsy, although invasive, is helpful in differentiating the cause of osteoporosis, including osteogenesis imperfecta and for guiding treatment. Osteogenesis imperfecta is associated with decreased cancellous bone volume, increased bone turnover and very thin bone cortices on bone biopsy. ${ }^{8}$ In our patient, bone histomorphometry was not done due to limited expertise.

DXA scan has been used to assess degree of osteoporosis by measuring bone mineral density. Alternative tools such as peripheral quantitative CT, high-resolution peripheral quantitative CT and MRI are used to capture bone geometry, microstructure and mass. ${ }^{2}$

Although spontaneous remission usually occurs in patients with IJO coinciding with puberty, permanent bone

Table 1 BMD readings and height-adjusted Z score for lumbar spine and left hip.

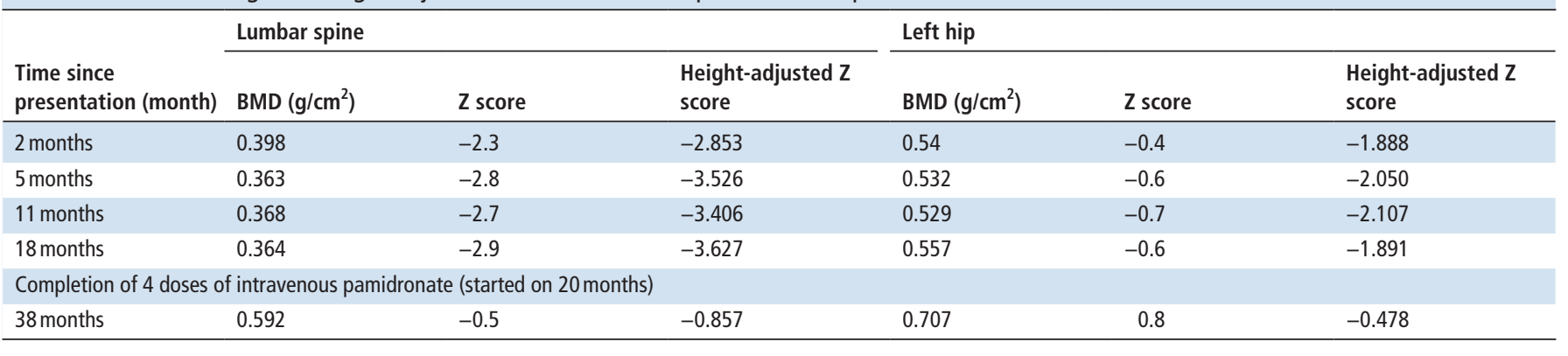


deformities may occur. ${ }^{9}$ Conservative management of IJO includes providing optimal vitamin $\mathrm{D}$ and calcium and avoidance of heavy backpacks that may overload the spine. The prevalence of 25-hydroxy $(\mathrm{OH})$ vitamin $\mathrm{D}$ deficiency in the cohort of patients with IJO analysed by Bacchetta et al and the association between $25(\mathrm{OH})$ vitamin D levels and parameters of skeletal mineralisation suggest that early detection and treatment of vitamin D deficiency and insufficiency may be beneficial. ${ }^{7}$ Our patient received his vitamin D supplementation for 4 years since his initial presentation. Patients with vertebral deformities should be referred to a paediatric spine specialist. High-impact physical activity should be avoided, but a programme of physical therapy appropriate to maintain gentle skeletal loading is recommended. ${ }^{2}$

The first case report regarding bisphosphonates treatment involved a $13^{1 / 2}$-year-old boy with IJO. The authors reported clinical, biochemical and radiological improvement post bisphosphonate treatment. ${ }^{10}$ Bisphosphonate therapy has resulted in pain relief and increments in areal bone mineral density in case reports and case series. ${ }^{11}{ }^{12}$ In Shaw et al's study, the patient with IJO was given three doses of intravenous pamidronate over 1 week, although the specific dosage was not described in the paper. ${ }^{11}$ Early intravenous bisphosphonate in the context of ongoing bone modelling has been shown to have beneficial effects on spinal morphology in primary osteoporosis. Sebestyen $e t \mathrm{al}^{13}$ reported that children with IJO and vertebral collapse fractures ceased pain medications and spine brace after intravenous administration of bisphosphonates.

Papakonstantinou et al ${ }^{14}$ described a 10 -year-old Caucasian girl in Tanner stage 2 who received alendronate sodium orally, $70 \mathrm{mg}$ per week for 6 months. Her back pain improved with the increment in $\mathrm{Z}$ score from -2.3 to -1.8 (DXA scan) 3 months post cessation of treatment. Nine patients with IJO were randomised to intravenous pamidronate $(0.8 \pm 0.1 \mathrm{mg} /$ $\mathrm{kg}$ per day for 3 days; cycles per year $2.0 \pm 0.1$; duration $7.3 \pm 1.1$ years; $n=5)$ or no treatment $(n=4)$ by Baroncelli et al. ${ }^{9}$ They found that pamidronate treatment stimulated the onset of recovery phase reducing fracture rate, causing higher lumbar bone mineral density area, higher bone marrow density volume $\mathrm{Z}$ score and reduced permanent disabilities without evidence of side effects. In comparison to our case report, we used a different dosage $(1 \mathrm{mg} / \mathrm{kg} / \mathrm{dose}$ once every 3 months for four doses in total) but resulted in clinical improvement in symptoms and height-adjusted $\mathrm{Z}$ score. In some centres, intravenous zoledronic acid is used as it is comparable to pamidronate in its efficacy and safety for treatment of osteoporosis in children. ${ }^{15}$ Although spontaneous remission is reported, resolution of spinal changes is not guaranteed. Therefore, the presence of vertebral compression fractures is an indication to treat with bisphosphonates. Larger studies comparing pamidronate to placebo would therefore not be ethical due to the risk of long-term vertebral involvement. Our case illustrated that even if bisphosphonates are used after a period of observation, it is useful to correct the vertebral geometry.

Serum parathyroid hormone levels were directly related to trabecular bone volume (positive correlation, $r=0.670$, $\mathrm{p}=0.024){ }^{7}$ Successful osteoporosis treatment with calcitonin has been reported in small numbers of children who had thalassaemia and renal disease; however, calcitonin has not proven its efficacy in the treatment of IJO, and therefore was not used in our patient. ${ }^{16} 17$
Learning points

- Paediatric osteoporosis can be classified into primary osteoporosis (eg, osteogenesis imperfecta, idiopathic juvenile osteoporosis) and secondary osteoporosis (endocrine causes, chronic diseases, glucocorticoid usage).

- Idiopathic juvenile osteoporosis is a rare, self-limiting disorder of bone pain and fractures. It is a diagnosis of exclusion.

- Spontaneous remission occurs in most patients with idiopathic juvenile osteoporosis, although permanent bone deformities can occur.

- There is a role for intravenous pamidronate, which reduces disability and fracture rate in idiopathic juvenile osteoporosis.

Contributors LOT: Contributed to conception and design; contributed to acquisition and analysis; drafted manuscript; agrees to be accountable for all aspects of work ensuring integrity and accuracy. SYL: Contributed to conception and design; contributed to acquisition and analysis; critically revised manuscript; agrees to be accountable for all aspects of work ensuring integrity and accuracy. RFV: Contributed to conception; contributed to interpretation; critically revised manuscript; gave final approval; agrees to be accountable for all aspects of work ensuring integrity and accuracy.

Competing interests None declared.

Patient consent Parental/guardian consent obtained.

Provenance and peer review Not commissioned; externally peer reviewed.

(c) BMJ Publishing Group Ltd (unless otherwise stated in the text of the article) 2017. All rights reserved. No commercial use is permitted unless otherwise expressly granted.

\section{REFERENCES}

1 Krassas GE. Idiopathic juvenile osteoporosis. Ann N Y Acad Sci 2000;900:409-12.

2 Ward L, Zulf Mughal M, Bachrach LK, et al. Chapter 43: Osteoporosis in Childhood and Adolescence. Osteoporosis, 2013:1037-86.

3 Brenton DP, Dent CE. Idiopathic juvenile osteoporosis. In: Bicket JH, Stern J, eds. Inborn Errors of Calcium and Bone Metabolism. Baltimore,MD: University Park Press, 1995:223-38.

4 Smith R. Idiopathic juvenile osteoporosis: experience of twenty-one patients. $\mathrm{Br}$ J Rheumatol 1995:34:68-77.

5 Altan H, Tosun G, Şen Y. Idiopathic Juvenile Osteoporosis: A Case Report. J Clin Diagn Res 2015:9:ZD10-12

6 Rauch F. Bishop N: Idiopathic juvenile osteoporosis. Rosen C, Primer on the metabolic bone diseases and disorders of mineral metabolism. 7. Washington: American Society for the Bone and Mineral Research, 2008:264-7.

7 Bacchetta J, Wesseling-Perry K, Gilsanz V et al. Idiopathic juvenile osteoporosis: a cross-sectional single-centre experience with bone histomorphometry and quantitative computed tomography. Pediatr Rheumatol Online J 2013;11:6.

8 Mäyränpää MK, Tamminen IS, Kröger H, et al. Bone biopsy findings and correlation with clinical, radiological, and biochemical parameters in children with fractures. J Bone Miner Res 2011:26:1748-58.

9 Baroncelli GI, Vierucci F, Bertelloni S, et al. Pamidronate treatment stimulates the onset of recovery phase reducing fracture rate and skeletal deformities in patients with idiopathic juvenile osteoporosis: comparison with untreated patients. J Bone Miner Metab 2013:31:533-43.

10 Hoekman K, Papapoulos SE, Peters AC, et al. Characteristics and bisphosphonate treatment of a patient with juvenile osteoporosis. J Clin Endocrinol Metab 1985;61:952-6.

11 Shaw NJ, Boivin CM, Crabtree NJ. Intravenous pamidronate in juvenile osteoporosis Arch Dis Child 2000;83:143-5.

12 Brumsen C, Hamdy NA, Papapoulos SE. Long-term effects of bisphosphonates on the growing skeleton. Studies of young patients with severe osteoporosis. Medicine 1997;76:266-83.

13 Sebestyen JF, Srivastava T, Alon US. Bisphosphonates use in children. Clin Pediatr 2012;51:1011-24.

14. Papakonstantinou O, Sakalidou M, Atsali E, et al. Radiographic and MR Imaging Findings of the Spine after Bisphosphonate Treatment, in a Child with Idiopathic Juvenile Osteoporosis. Case Rep Radiol 20152015;2015:1-4.

15 Al-Agha AE, Hayatalhazmi RS. Osteoporosis treatment with zoledronic acid in pediatric population at a university hospital in Western Saudi Arabia. A 13-year experience. Saudi Med J 2015:36:1312-8.

16 Steelman J, Zeitler P. Osteoporosis in pediatrics. Pediatr Rev 2001;22:56-65. 


\section{Rare disease}

17 Jackson EC, Strife CF, Tsang RC, et al. Effect of calcitonin replacement therapy in

Copyright 2017 BMJ Publishing Group. All rights reserved. For permission to reuse any of this content visit http://group.bmj.com/group/rights-licensing/permissions.

BMJ Case Report Fellows may re-use this article for personal use and teaching without any further permission.

Become a Fellow of BMJ Case Reports today and you can:

- Submit as many cases as you like

- Enjoy fast sympathetic peer review and rapid publication of accepted articles

- Access all the published articles

- Re-use any of the published material for personal use and teaching without further permission

For information on Institutional Fellowships contact consortiasales@bmjgroup.com

Visit casereports.bmj.com for more articles like this and to become a Fellow 